\title{
BE THE MOVEMENT
}

\section{International Workshop in parallel to COP19/CMP9 (Warsaw, Poland, 11 ${ }^{\text {th }}-22^{\text {nd }}$ November, 2013)}

In November $2013\left(11^{\text {th }}-22^{\text {nd }}\right)$, Warsaw hosted the 19th International Conference of the Parties (COP 19) to The United Nations Framework Convention on Climate Change (UNFCCC). The Conference has also served as the $9^{\text {th }}$ Meeting of the Parties to the Kyoto Protocol (CMP 9). The COP19/CMP9 Conference brought together hundreds of politicians, researchers and NGO activists discussing the possibilities for climate change to be mitigated. The Conference was accompanied by several workshops.

Connect4Climate 1 and the Faculty of Geography and Regional Studies of the University of Warsaw co-hosted Be the Movement, an international Workshop addressing the means of expanding and strengthening the global climate change movement. The daylong workshop focused on strategies for attracting greater participation, especially from young people, in the movement.

The event's dominant theme - expressed in its title, Be the Movement - was that each person can make a difference when it comes to climate change, by taking individual actions in the mitigation of global warming.

The Workshop drew more than 350 attendees representing 50 countries, including prominent climate change activists and scientists, representatives of the media, private sector companies, NGOs, and international organizations, as well as students and concerned citizens. The workshop also reached an online audience of more than 300000 Twitter users in a day.

1 Conect4Climate is a World Bank Group initiative aimed at raising global awareness of climate change and inspiring climate action. It was founded in 2011 by WBG, together with the Italian Ministry of Environment, and the Global Environment Facility. The objectives of C4C involve connecting with existing climate initiatives and activities and amplifying the global dialogue on climate change. 
The Workshop consisted of two complementary parts. During its morning session, 85 participants broke up into small brainstorming groups to devise creative ways of strengthening five vital areas of concern to the climate change movement, namely:

- communicating climate change to new audiences,

- empowering educators to give environmental information,

- innovating new climate change campaign strategies,

- considering costs (and demonstrating that economic development does not conflict with climate change mitigation policies), and

- inspiring bold leadership to spark climate solutions.

In the afternoon the Plenary Session of the Workshop took place with the participation of about 350 attendees, mainly secondary and high level students. The Plenary Session consisted of several sections:

- Breakout Sessions: Five Vital Needs of the Climate Change Movement, which summarized morning discussions;

- a Climate Interview with Professor Zbigniew W. Kundzewicz;

- Pecha Kucha presentations (10-min presentations from climate change experts);

- a Panel Discussion with leading figures in the climate change movement: David Cadman (President of the International Council for Local Environmental Initiatives), Kelly Rigg (Executive Director of the Global Call for Climate Action), Jamie Henn (Communications Director of 350.org) and Wael Hmaidan (Director of the Climate Action Network)

- Motivational Speeches: Calls for Climate Action made by Rachel Kyte (World Bank Group Vice President and Special Envoy on Climate Change), Corrado Clini (Director General of Italy's Ministry of Environment), Yvo de Boer (KPMG's Special Global Advisor on Climate Change and Sustainability), Nick Nuttal (Director of the Division of Communications and Public Information of the UN Environmental Programme) and Peter Bakker (President of the World Business Council for Sustainable Development).

Finally, displaying the enthusiasm for climate change action that the Workshop had kindled in them, representatives of Polish student participants read a pledge of action (Appendix 1).

During morning brainstorming discussions the participants addressed problems crucial to actions capable of mitigating climate change. Tan Copsey and Eliza Anyangwe led the small group discussion on ways to communicate more effectively with new audiences to draw them into the climate change movement and thus expand its reach. They concluded that the following are key aspects to any successful climate change campaign:

- We must know our audience. The audience group (rural-urban, middle classlow income, coastal-desert, highly educated-illiterate) determine the campaign's theme;

- Determining the most appropriate communication channels (face-to-face conversations, TV, radio, social media, posters) and formats must depend on the target audience; 
- Asking the targeted audience about their personal, everyday experiences with climate change is crucial to the development of a meaningful campaign theme;

- Choosing partners (individuals, agencies, politicians, business leaders, community organizers, academics, NGOs, local media) is conditioned by the identification of those who are influential with the targeted audience;

- Including real, practical, and easily implemented solutions to environmental problems in the campaign message to targeted audiences is important.

Krzysztof Blażejczyk chaired the group discussion on empowering educators. Participants concluded that:

- While schoolchildren form one of the audiences most interested in climate change, an essential goal of the movement should be to help educators transfer climate change knowledge;

- Children are an important audience because they are likely to educate their parents and persuade them to change their environmental habits;

- Contrary to popular belief, children are capable of understanding complicated environmental processes if the language used is comprehensible to them;

- The most efficient method of introducing environmental knowledge is combining scientific information with emotional content;

- There should be an emphasis on the practical side and on showing possible courses of action to mitigate and adapt to climate change;

- Teachers should be encouraged to show connections between their academic discipline and the environment. To do this, they must not only be educated in their own discipline, and should be encouraged by bodies responsible for administering education;

- Teachers and parents should be role models for good environmental stewardship, so that what children learn in the classroom becomes practical and second nature to them;

- Social media can raise environmental awareness among young people, with portals like Facebook and Twitter representing some of the best ways to reach youth.

David Millard chaired the small group that considered ways to enhance movement strategies and to identify missing ingredients in those strategies. The group concluded that:

- Effective campaigns must be sustainable, and short-term events are better than long-term ones. However, short-term events should be repeated at regular intervals and be integrated into larger, long-term campaigns to secure permanent change in society's environmental attitudes;

- Climate change awareness should begin in primary schools, because positive attitudes are easy to shape in children;

- Campaigns should be designed specifically for their audience;

- The most successful campaigns give high priority to personal connections and relationships; 
- Internet-only campaigns are sometimes ineffective because they do not reach lowincome or poor communities who generally suffer most from climate change's harmful effects;

- Visuals that bring home the tangible detriments of climate change are important in getting communities to accept the message of any campaign.

Zbigniew W. Kundzewicz led the small group discussion on costs; this group examined economic issues relating to climate change, in particular, the costs of greenhouse gas emissions. This particular group concluded that:

- Energy production costs should include the harm inflicted on the environment and society (negative externalities);

- Economic growth is not always blocked by measures to reduce greenhouse gas emissions, and investing in such reduction efforts will have only a minor impact on overall economic growth;

- Energy production decisions are not always predictable.

Antonio Navarra led the discussion on leading for solutions. This group's conclusions were that:

- A consistent message from the climate change movement should help make it clear that the twin goals of global economic development and climate protection are not in conflict;

- Green energy is the key to effective mitigation of climate change and greenhouse gas emissions in the future;

- Change needs to be driven from the grassroots, and individuals and communities must develop real action;

- Government officials not usually involved in the global climate change conversation - such as Ministers of finance and economic development - need to be brought into this discussion;

- More emphasis needs to be placed on educating today's young people. At the moment, young people are not involved enough in the climate change movement, and there is no lobbying effort for drawing in future generations.

A very informative element of the afternoon sessions entailed an interview with Professor Zbigniew W. Kundzewicz carried out by Eliza Anyangwe of British newspaper The Guardian. They start with essential information from the IPCC's Fifth Assessment Report in which Profesor Kundzewicz was a lead author of one of the chapters. Concluding, the Professor emphasized how one person can make a difference. He said: We can do a lot by changing our habits, by doing things that make sense anyway. It's always good to save energy, to save water.

In the Pecha Kucha section the audience had the possibility to share several experiences from different climate change actions. Michelle Kovacevic from the Center for International Forestry Research (CIFOR) presented her organization's approach to 
climate communication solutions, introducing three different aspects: (a) the challenges CIFOR faces in crafting its messages, (b) the models used to communicate these messages, and (c) media and methods chosen to reach and resonate with audiences. Sepo Hachigonta, who is responsible for coordinating the Food, Agriculture, and Natural Resources Policy Analysis Network's climate change projects, highlighted the role of government policies in addressing food and nutrition security in the light of the climate threat. Marion Davis, from the Stockholm Environmental Institute, pointed out another aspect of the communication challenge: language and cultural barriers. Camilla Torpe, Event Manager at the Danish toy firm LEGO, discussed one of the company's engagement activities - Build the Change - in which children are given LEGO to build environmentally friendly structures. Moritz Weigel from the UNFCCC introduced the UN Alliance for Climate Change Education, Training, and Public Awareness, launched during the previous COP18 in December 2012. Weigel described how the Alliance is composed and listed its member organizations.

Of major interest was the panel discussion of climate movement experts. Each panellist presented his or her organization's mission, goals, and activities. They also spoke about the urgency need for climate action, the behavioural changes that the younger generations needed to make, and the need for young people to engage and inspire others.

The young students who participated in Be the Movement Workshop were so inspired by all the discussions, presentations and motivational speeches that they decided to proclaim a special Warsaw Pledge, in which they express their needs and expectation in regard to climate actions. The students declared also, picking up on the Workshop that Whatever sacrifices we have to make now, we firmly believe our passion for this movement will spur global action to secure better livelihoods for humankind.

Krzysztof Błażejczyk Faculty of Geography and Regional Studies University of Warsaw 


\section{\) THE 2013 WARSAW \\ BE THE MOVEMENT \\ YOUTH PLEDGE}

\section{\#c4cMovement}

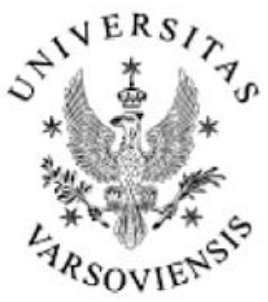

We, the participants of "Be The Movement", a global forum organized by the University of Warsaw and Connect4Climate on this day, November 20, 2013, jointly and solemnly declare:

1. We are fully aware that climate change is a dangerous threat not just to our generation, but to our sons and daughters, and all future generations.

2. We and all our fellow citizens on Earth have a duty to tackle the climate change emergency right now and to change our life styles accordingly.

3. While respecting diverse opinions, we should come together to reinforce our common potential and drive collective action to conserve the environment.

4. We expect that:

Researchers will provide us with objective data and seek innovative solutions for climate change,

Educators will assist us in passing on knowledge and awareness to students,

Local governments will support our activities to make sure our communities continue to be liveable and vital,

The private sector will commit to including climate change considerations in all its business planning,

$>$

The media will impartially report all information to raise awareness and encourage open discussion,

National governments will create legislation to enable greater conservation of our planet and its climate.

5. Whatever sacrifices we have to make now, we firmly believe our passion for this movement will spur global action to secure better livelihoods for humankind.

6. We will 'Be The Movement'! Right here, right now, together! 